\title{
Stage II Pancreatic Cancer AJCC v8
}

National Cancer Institute

\section{Source}

National Cancer Institute. Stage II Pancreatic Cancer A/CC v8. NCI Thesaurus. Code C134921.

Stage II includes: IIA: (T3, N0, M0); IIB: (T1, N1, M0); (T2, N1, M0); (T3, N1, M0). T1:

Tumor measuring $2 \mathrm{~cm}$ or less in greatest dimension. T2: Tumor measuring more than

$2 \mathrm{~cm}$ and $4 \mathrm{~cm}$ or less in greatest dimension. T3: Tumor measuring more than $4 \mathrm{~cm}$ in greatest dimension. N0: No regional lymph node metastasis. N1: Metastasis in one to three regional lymph nodes. M0: No distant metastasis. (AJCC 8th ed.) 